\title{
Production of cytokines by mononuclear cells of hypertrophic adenoids in children with otitis media with effusion
}

\author{
Beata Zelazowska-Rutkowska1, Elzbieta Ilendo1, Bozena Skotnicka², \\ Jolanta Wysocka1, Edwina Kasprzycka ${ }^{1}$
}

\author{
${ }^{1}$ Department of Pediatric Laboratory Diagnostics, Medical University of Bialystok, Poland \\ ${ }^{2}$ Department of Pediatric Otolaryngology, Medical University of Bialystok, Poland
}

\begin{abstract}
Hypertrophic adenoids with otitis media with effusion is a common infectious disease and present a serious otological problem in children. Cytokines, potent inflammatory mediators, play important role in the initiation of immunological response in otitis media. Adenoids excised due to hypertrophy with or without chronic otitis media with effusion were used to isolate mononuclear cells. Secretion of cytokines by non-stimulated and PHA-stimulated cells was determined by specific ELISAs. We found a significant increase in the production of IL-5 and TNF- $\alpha$ secreted by adenoidal cells of children with otitis media with effusion compared to group with hypertrophic adenoids. No differences were found in the secretion of IL-8, IL-6, and IL-10 between these two groups of patients. Our results suggest a difference between the immunological responses in the course of hypertrophic adenoids with otitis media as compared to hypertrophic adenoids. (Folia Histochemica et Cytobiologica 2012, Vol. 50, No. 4, 586-589)
\end{abstract}

Key words: adenoid tissue, IL-5, TNF- $\alpha$, otitis media, effusion

\section{Introduction}

The adenoids together with palatine tonsils and smaller aggregates of lymphatic tissue constitute the protective barrier of the body against antigens from the external environment [1]. Their anatomic location causes that they are first place of contact to many pathogenic factors. The adenoids take part in the humoral and cellular responses thanks to the presence of $\mathrm{B}$ and $\mathrm{T}$ cells, monocytes, NK cells and dendritic cells $[2,3]$. In the pharyngeal tonsil, $T$ cells cooperate with B cells, stimulate their differentiation, maturation and production of antibodies following direct stimulation by a signal transferred via $\mathrm{T}$ cells

\footnotetext{
Correspondence address: B. Zelazowska-Rutkowska, Department of Pediatric Laboratory Diagnostics, Medical University of Bialystok,

Waszyngtona St. 17, 15-274 Białystok, Poland; tel.: +48 857450743 ;

e-mail: zelazowskab@wp.pl
}

and dendritic cells [4]. The processes of lymphocyte stimulation, activation, proliferation and differentiation are controlled by cytokines. Depending on the stimulating agent, immunologically competent cells secrete a number of induction-phase factors, such as IL-1, or IL-12. Lymphocytes stimulated by these factors undergo transformation into Th1 and Th2 cells [5]. Main cytokines of the Th1 group include IL-2, IL-12, IFN- $\gamma$ and TNF- $\alpha$, whereas main factors secreted by Th 2 cells are IL-4, IL-5, IL- 6 and IL-10 [6, 7]. Proper cooperation between these cells and the cytokines determines the course and intensity of the inflammatory process.

The study objective was to assess the levels of IL-5, IL-6, IL-8, IL-10 and TNF- $\alpha$ in PHA (phytohemagglutinin) stimulated and in non-stimulated cell cultures isolated from tonsils in the group of children with hypertrophic adenoids who suffered from otitis media with effusion of at least three months' duration and children with hypertrophic adenoids without otitis media. 
Table 1. Secretion of IL-8, IL-10, IL-5, IL-6, TNF- $\alpha$ by non-stimulated and PHA stimulated mononuclear cells isolated from hypertrophic adenoids and hypertrophic adenoids of children with otitis media.

\begin{tabular}{|l|l|c|c|}
\hline \multicolumn{2}{|l|}{ CCytokine levels } & $\begin{array}{c}\text { Hypertrophic adenoid } \\
\text { with otitis media }(\mathbf{O M E})(\mathbf{n}=\mathbf{3 0})\end{array}$ & $\begin{array}{c}\text { Hypertrophic adenoid } \\
\text { without otitis media }(\text { HA) }(\mathbf{n}=\mathbf{3 5})\end{array}$ \\
\hline Gr IL-8 $[\mathbf{p g} / \mathbf{m L}]$ & UN & $418,3 \pm 203,7$ & $369,5 \pm 245,0$ \\
\hline & PHA & $936,6 \pm 482,4$ & $841,4 \pm 364,1$ \\
\hline ILIL-10 [pg/mL] & UN & $64,0 \pm 41,7$ & $80,9 \pm 64,7$ \\
\hline & PHA & $250,1 \pm 168,3$ & $247,5 \pm 110,2$ \\
\hline IL-5 $[\mathbf{p g} / \mathbf{m L}]$ & UN & $3,19 \pm 0,71 \&$ & $2,56 \pm 0,54$ \\
\hline & PHA & $26,71 \pm 42,71 *$ & $3,65 \pm 2,12$ \\
\hline ILIL-6 $[\mathbf{p g} / \mathbf{m L}]$ & UN & $12,45 \pm 20,67$ & $8,79 \pm 10,75$ \\
\hline & PHA & $120,1 \pm 102,7$ & $114,3 \pm 69,3$ \\
\hline TTNF- $\boldsymbol{\alpha}[\mathbf{p g} / \mathbf{m L}]$ & UN & $14,98 \pm 15,25$ & $10,53 \pm 7,83$ \\
\hline & PHA & $545,1 \pm 303,2 *$ & $344,7 \pm 242,5$ \\
\hline
\end{tabular}

Mononuclear cells isolated from adenoids were cultured for 48 hours either in the absence (UN, non-stimulated) or presence of phytohemagglutinin (PHA). ${ }^{*} \mathrm{p}<0.05 v$. HA group; ${ }^{*} \mathrm{p}<0.01 v$. HA group

\section{Material and methods}

The study material contained adenoids excised from 30 children (age range 3-17) suffering from adenoid hypertrophy coexisting with otitis media with effusion (OME) lasting at least 3 months. The reference group consisted of 35 children of both sexes (age range 3-17) with adenoid hypertrophy (HA) but without otitis media lasting at least 3 months. All children were clinically free of infection at the time of surgery. The children were qualified for adenoidectomy in the Department of Children's Otolaryngology of the Medical University of Bialystok. The study was approved by the Bioethical Committee, Medical University of Bialystok, number R-I 002/287/2009.

Immediately after excision adenoids were placed in RPMI 1640 culture medium containing 10\% fetal calf serum (Immuniq). Then, they underwent mechanical grinding so as to give a homogenous suspension. The suspension was centrifuged for $1 \mathrm{~min}$. at $4^{\circ} \mathrm{C}($ at $150 \times g)$. The obtained supernatant containing leukocytes, was subjected to further analysis. Cells were obtained from the supernatant through centrifugation for $8 \mathrm{~min}$ at $4^{\circ} \mathrm{C}($ at $300 \times g)$, and then rinsed with PBS containing $0.1 \mathrm{mM}$ EDTA and $0.02 \% \mathrm{NaN}_{3}$ (SigmaAldrich), and centrifuged again for $8 \mathrm{~min}$. at $4^{\circ} \mathrm{C}($ at $300 \times g)$.

The density of cell suspension was assessed in a hematologic analyzer Sysmex XT 2000i and cell morphology was checked microscopically. Cell suspensions of $4-10 \times 10^{3} / \mu \mathrm{l}$ density were used for analyses.

Cells from adenoid tissue were added, respectively, at the density of $2 \times 10^{5}$ per well in 10\% RPMI1640 medium supplemented with $100 \mathrm{U} / \mathrm{mL}$ penicillin (Polfa Tarchomin),
$50 \mu \mathrm{g} / \mathrm{mL}$ streptomycin (Polfa Tarchomin) and PHA $4 \mu \mathrm{g} / \mathrm{mL}$ (SigmaAldrich) in round-bottom 96-well tissue culture plates. The plates were incubated at $37^{\circ} \mathrm{C}$ in a humidified incubator containing $5 \%$ carbon dioxide.

Supernatants of cell cultures were collected $48 \mathrm{~h}$ after stimulation and stored at $-80^{\circ} \mathrm{C}$ until cytokine analyses were performed. The levels of IL-5, IL-6, IL-8, IL-10, TNF- $\alpha$ were quantified using commercial ELISA kits according to manufacturer's instruction (R\&D Systems). Staining intensity was measured spectrophotometrically with the use of a microplate reader ELISA (ANTHOS, Australia) at $450 \mathrm{~nm}$ with the correction wavelength set at $570 \mathrm{~nm}$. The results were calculated based on the lineary standard curve and expressed as $\mathrm{pg} / \mathrm{mL}$. The minimal levels of detection were (all in pg/mL) 3,0 for IL-5, 0,70 for IL-6, 3, 5 for IL-8, 3, 9 for IL-10 and 1, 6 for TNF- $\alpha$.

Statistical analysis. Non-parametric U Mann-Whitney test was used to analyze differences regarding the production for IL-5, IL-6, IL-8, IL-10, TNF- $\alpha$. The differences for $\mathrm{p}<0,05$ were considered statistically significant. The results were expressed as the mean and standard deviation (Table 1).

\section{Results}

The production of IL- 8 , IL- 6 , IL-10, TNF- $\alpha$ in the cultures supernatant of non-stimulated cells (spontaneous production) was similar in cells isolated from hypertrophic adenoids of patients with otitis media with effusion (OME group) compared to cells from hypertrophic adenoids of patients without otitis media (HA group). IL-5 production in a non-stimulated 
culture was significantly higher in OME group than in HA patients (Table 1).

Statistical analysis showed much higher IL-5 production in cell cultures stimulated with PHA in the OME group than in the reference HA group (Table 1). The mean level of TNF- $\alpha$ production in stimulated cells from hypertrophic adenoids of children with otitis media with effusion (OME) was higher compared to the children with HA alone (Table 1). There were no differences in the levels of IL-6, IL-8 and IL-10 in supernatants of cells isolated from children with hypertrophic adenoids with otitis media with effusion compared to children with hypertrophic adenoids but without otitis media (Table 1).

\section{Discussion}

Cytokines play an important role in the immune system as they mediate and regulate immune and inflammatory reactions [8]. Two basic types of Th lymphocytes produce two distinct patterns of cytokines. Type 1 cytokines primarily promote cell mediated immunity, they are involved as pro-inflammatory cytokines and promote synthesis of antibodies by B cells. Type 2 cytokines are required for the production of other cytokine types and also promote humoral immunity $[8,9]$.

The underlying mechanisms responsible for the initiation and perpetuation of inflammation in the hypertrophic adenoid in children with otitis media with effusion are unclear. Previously, we demonstrated that lymphocyte apoptosis in hypertrophic adenoids in children with otitis media with effusion was more enhanced than in the HA group. This was probably due to the fact that in hypertrophic adenoids of OME children the percentage of $\mathrm{CD} 4^{+}$and $\mathrm{CD} 8^{+}$lymphocytes with Fas expression was higher compared to the group without inflammation, whereas the percentage of these cells with Bcl-2 expression was lower [10]. The tendency of reduced proportion of $\mathrm{T}$ and $\mathrm{B}$ lymphocytes with $\mathrm{Bcl}-$ 2 expression and elevated proportion of these cells with $\mathrm{CD}^{2} 5^{+}$expression within the adenoids may reflect disorders of local immunity. We showed also that part of this effect could be caused by differences in the function of dendritic cells [11].

There is an ample evidence that microorganisms that infect the middle ear in bacterial otitis media (Streptococcus pneumoniae, Haemophilus influenzae, Moraxella catarrhalis, Staphylococcus aureus) originate in the adenoids [12-14]. Different cytokines play key roles in innate immunity to different classes of microbes. Agren et al. reported that $H$. influenzae induced Th1 cytokines in human tonsillar lymphocytes [15]. Harimaya et al. demonstrated that Alloiococcus otitidis induced the activation of lymphocytes and the re- lease of Th1 promoting cytokines (IL-12 and IFN- $\gamma$ ) during the early phase of the immune response [16].

Many authors investigated cytokine production by adenoidal lymphocytes [17-19]. Boyaka et al, who analysed PHA-stimulated adenoid mononuclear cells, reported secretion of IFN- $\gamma$, IL-4, IL-5, IL-10 [4]. Interestingly, cultures with a high proliferative response secreted higher levels of the Th2-type cytokines (IL-4, IL-5, IL-10) compared with IFN- $\gamma$ and the opposite was noted for the cultures with low proliferative response. However, the atopic status of the children included was not investigated, what means that the children with higher levels of Th-2 type cytokines could be as well atopic [4].

IL-5 and IL-4 are Th2 cytokines involved in the development of human immune responses. Increased production of these cytokines in middle ear effusion and adenoid tissues was found in children with atopy [20]. Nguyen et al demonstrated significantly higher levels of eosinophils, T lymphocytes and IL-4 and IL-5 in atopic middle ear effusions compared with non-atopic patients [21].

Increased IL-5 production, found also in our study, may be beneficial for the host, because these cytokine are important in the stimulation of the production of antibodies that would be responsible for a humoral immune response directed against potential pathogens [21].

IL-8, one of the strongest chemotactic factors, especially for neutrophils, plays an important role in exudative otitis media. It is secreted by macrophages, monocytes, B lymphocytes and neutrophils. Its synthesis is stimulated by IL- 1 and TNF- $\alpha$, and inhibited by interferon $\alpha$ and $\beta$. It was reported that in the course of acute otitis media the level of IL- 8 increased in a later stage of the disease and its presence is associated with a tendency to relapse and transition to the chronic phase [22].

IL-10 has direct effects on B cells, including prevention of apoptosis, enhancement of proliferation and differentiation of plasma cells [23]. IL-10 was shown to be capable to inhibit synthesis of pro-inflammatory cytokines like IFN- $\gamma$, IL-2 and IL-3 [24, 25]. T-cell derived IFN- $\gamma$ and IL-10 may be key regulators of the production of mucosal antibody to pneumococcal protein antigens in the nasopharynx and may play an important role in local protection against pneumococcal infection in children [26].

Komorowska et al. demonstrated increased secretion of IL-2, IL-4, IL-5, TNF- $\alpha$ and IFN- $\gamma$ from PHA-activated immune cells isolated from palatine tonsils. They found that in palatine tonsils compared to adenoids the cellular immune Th1-type proinflammatory response dominated over immune Th2- type 
reaction [27]. Our results clearly suggest that in the adenoid tissue of children suffering from otitis media with effusion the prevailing $\mathrm{T}$ cell response was of the Th2 type due to the higher production of IL-5. Our findings are in support of previous observations by Bernstein et al. [28]. They found a decrease in the synthesis of Th1 cytokines IL-2 and IFN- $\gamma$ in lymphoid tissue of patients with both recurrent otitis media and hypertrophic adenoids. In contrast, Th2 cytokines were synthesized in similar quantities. These authors suggested that persistence of Th2 cytokines over Th1 cytokines could contribute to a chronic inflammatory state [28].

In conclusion, our results suggest a difference between the immunological responses in the course of hypertrophic adenoids with otitis media as compared to hypertrophic adenoids.

\section{References}

1. Brandtzaeg P. Function of mucosa-associated lymphoid tissue in antibody formation. Immunol Invest. 2010;39:303-355.

2. Freud AG, Caligiuri MA. Purification of human NK cell developmental intermediates from lymph nodes and tonsils. Methods Mol Biol. 2010;612:1-14.

3. Llinàs L, Lázaro A, de Salort J, Matesanz-Isabel J, Sintes J, Engel P. Expression profiles of novel cell surface molecules on B-cell subsets and plasma cells as analyzed by flow cytometry. Immunol Lett. 2011;134:113-121.

4. Boyaka PN, Wright PF, Marinaro M, Kiyono H, Jonhson JE, Gonzales R.A et al. Human nasopharyngeal-associated lymphoreticular tissues. Functional analysis of subepithelial and intraepithelial $\mathrm{B}$ and $\mathrm{T}$ cells from adenoids and tonsils. Am J Pathol. 2000;157:2023-2035.

5. Diehl S, Rinco'n M. The two faces of IL-6 on Th1/Th2 differentiation. Mol Immunol. 2002;39:531-536.

6. Harber M, Sundstedt A, Wraith D. The role of cytokines in immunological tolerance: potential for therapy. Exp Rev Mol Med. 2000;27: 1-20.

7. Borish LC, Steinke JW. Cytokines and chemokines. J Allergy Clin Immunol. 2003;111: S460-S475.

8. Mosmann TR, Sad S. The expanding universe of T-cell subsets: Th1, Th2 and more. Immunol Today. 1996;9:138-146.

9. Spellberg B, Edwards JE. Type 1/Type 2 immunity in infectious diseases. Clin Infect Dis. 2001; 32:76-102.

10. Żelazowska-Rutkowska B, Wysocka J, Skotnicka B. Chosen factors of $\mathrm{T}$ and $\mathrm{B}$ cell apoptosis in hypertrophic adenoid in children with otitis media with effusion. Int J Pediatr Otorhinolaryngol. 2010;74:698-700.

11. Żelazowska-Rutkowska B, Ratomski K, Wysocka J, Kasprzycka E, Hassmann-Poznańska E, Mrugacz M. Dendritic cells in hypertrophied adenoid at children with otitis media with effusion. [Article in Polish]. Otolaryngol Pol. 2009;63:348-52.

12. Averono G, Vidali M, Olina M, Basile M, Bagnati M, Bellomo G. et al. Evaluation of amoxicillin plasma and tissue levels in pediatric patients undergoing tonsillectomy. Int $J$ Pediatr Otorhinolaryngol. 2010; 74:995-998.
13. Lin CD, Tsai MH, Lin CW, Ho MW, Wang CY, Tsou YA et al. Association of adenoid hyperplasia and bacterial biofilm formation in children with adenoiditis in Taiwan. Eur Arch Otorhinolaryngol. 2012;269:503-511.

14. Harimaya A, Fujii N, Himi T. Preliminary study of proinflammatory cytokines and chemokines in the middle ear of acute otitis media due to Alloiococcus otitidis. Int J Pediatr Otorhinolaryngol. 2009;73:677-680.

15. Agren K, Brauner A, Andersson J. Haemophilus influenzae and Streptococcus pyogenes group A challenge induce a Th1 type of cytokine response in cells obtained from tonsillar hypertrophy and recurrent tonsillitis. ORL J. Otorhinolaryngol Relat Spec. 1998;60:35-41.

16. Harimaya A, Tarkkanen J, Mattila P, Fujii N, Ylikoski J, Himi T. Difference in cytokine production and cell activation between adenoidal lymphocytes and peripheral blood lymphocytes of children with otitis media. Clin Diagn Lab Immunol. 2005;12:1130-1134.

17. Diehl S, Rinco'n M. The two faces of IL-6 on Th1/Th2 differentiation. Mol Immunol. 2002;39:531-536.

18. Harimaya A, Tarkkanen J, Mattila P, Fujii N, Ylikoski J, Himi T. Difference in cytokine production and cell activation between adenoidal lymphocytes and peripheral blood lymphocytes of children with otitis media. Clin Diagn Lab Immunol. 2005; 12:1130-1134.

19. Skotnicka B, Hassmann E. Proinflammatory and immunoregulatory cytokines in the middle ear effusions. Int J Pediatr Otorhinolaryngol. 2008;72:13-17.

20. Papatziamos G, van Hage-Hamsten M, Halden G, Lundahl J, Hemlin C. Increased levels of IL-2 and IL-4 in stimulated adenoidal lymphocytes of atopic children. Int Arch Allergy Immunol. 2003;132:29-35.

21. Nguyen LH, Manoukian JJ, Sobol SE, Tewfik TL, Mazer BD, Schloss MD et al. Similar allergic inflammation in the middle ear and the upper airway: evidence linking otitis media with effusion to the united airways concept. J Allergy Clin Immunol. 2004;114:1110-1115.

22. Chonmaitree T, Patel JA, Sim T, Garofalo R, Uchida T, Sim T et al. Role of leukotriene B4 and interleukin-8 in acute bacterial and viral otitis media. Ann Otol Rhinol Laryngol. 1996;105:968-974.

23. Levy Y, Brouet JC. Interleukin-10 prevents spontaneous death of germinal center B cells by induction of the bcl-2 protein. J Clin Invest. 1994;93:424-428.

24. Groux H, Cottrez F. The complex role of interleukin-10 in autoimmunity. J Autoimmun. 2004;20:281-285.

25. Zhang Q, Bernatoniene J, Bagrade L, Paton JC, Mitchell TJ, Hammerschmidt $\mathrm{S}$. et al. Regulation of production of mucosal antibody to pneumococcal protein antigens by T-cell-derived gamma interferon and interleukin-10 in children. Infect Immun. 2006;74:4735-4743.

26. Hopkins SJ. The pathophysiological role of cytokines. Leg Med. 2003;5:S45-S57.

27. Komorowska A, Komorowski J, Banasik M, Lewkowicz P, Tchórzewski H. Cytokines locally produced by lymphocytes removed from the hypertrophic nasopharyngeal and palatine tonsils. Int J Pediatr Otorhinolaryngol. 2005;69:937-941.

28. Bernstein JM, Ballow M, Xiang S, O'Neil K. Th1/Th2 cytokine profiles in the nasopharyngeal lymphoid tissues of children with recurrent otitis media. Ann Otol Rhinol Laryngol. 1998;107:22-27. 